\title{
Ceftriaxone or HIV associated angio-oedema? Case report
}

\author{
William Macharia \\ Aga Khan University, macharai.william@aku.edu \\ C. Mbaabu \\ University of Nairobi \\ L. Wachira \\ Gertrude's Garden Children's Hospital \\ S.O.M. Muhudhia \\ Children's Clinic \\ G. Moniz \\ Children's Clinic
}

Follow this and additional works at: https://ecommons.aku.edu/eastafrica_fhs_mc_paediatr_child_health

Part of the Pediatrics Commons

\section{Recommended Citation}

Macharia, W., Mbaabu, C., Wachira, L., Muhudhia, S., Moniz, G. (2005). Ceftriaxone or HIV associated angio-oedema? Case report. East African Medical Journal, 82(11), 598-600.

Available at: https://ecommons.aku.edu/eastafrica_fhs_mc_paediatr_child_health/16 
East African Medical Journal Vol. 82 No. 11 November 2005 CEFTRIAXONE OR HIV ASSOCIATED ANGIO-OEDEMA? CASE REPORT

W. M. Macharia, MBChB, MMed., MSc., Department of Paediatrics and Child Health, College of Health Sciences, University of Nairobi, P.O. Box 19676, Nairobi, Kenya, C. Mbaabu, KRN, KRM, ICN, L. Wachira, KRCHN, Gertrude's Garden Children's Hospital, P. O. Box 42325, Nairobi, Kenya, S. O. M. Muhudhia, MBChB, MMed, and G. Moniz, MBChB, MMed, Children's Clinic, Hesabu House, P.O. Box 7630-00508, Nairobi, Kenya

Request for reprints to: Prof. W. M. Macharia, Department of Paediatrics and Child Health, College of Health Sciences, University of Nairobi, P. O. Box 19676, Nairobi, Kenya

\title{
CEFTRIAXONE OR HIV ASSOCIATED ANGIO-OEDEMA? CASE REPORT
}

\author{
W. M. MACHARIA, C. MBAABU, L. WACHIRA, S. O. M. MUHUDHIA and G. MONIZ
}

\section{SUMMARY}

\begin{abstract}
Angio-oedema may be hereditary or acquired and is characterised by episodes of potentially life threatening localised tissue oedema and swelling resulting from deficiency of compliment pathway $\mathrm{C} 1$ esterase inhibitor. Acquired angio-oedema is about ten times less frequent than the hereditary type and has been associated with immune-deficiency disorders, malignancies and exposure to specific medications and food substances. We present a case of seven year old, human immune-deficiency virus positive girl, who developed gross swelling of the tongue and neck while on treatment for pneumococcal meningitis with ceftriaxone. Difficulties in arriving at a definitive diagnosis of angiooedema in a resource poor country are discussed and alternative diagnostic options proposed.
\end{abstract}

\section{INTRODUCTION}

Angio-oedema is a fairly uncommon clinical syndrome characterised by episodes of potentially life threatening localised tissue oedema and swelling resulting from either hereditary or acquired deficiency of compliment pathway $\mathrm{C} 1$ esterase inhibitor. Classically, the swelling develops gradually over several hours, increasing slowly over 12-36 hours and then subsides over two to five days. Episodes resulting in upper respiratory tract, including tongue, pharynx and larynx, carry an estimated mortality rate of about $15-33 \%$ (1). Most of the literature on this condition is based on small case series and case reports. More than 100 different $\mathrm{C} 1$ inhibitor gene mutations have been described in the hereditary type which is transmitted in an autosomal dominant manner with a mutation rate of about $25 \%$ (2).

Acquired angio-oedema (AAE) is about ten times less frequent than the hereditary type and more often presents in older patients in association with lymphoproliferative diseases, infections or autoimmune disorders $(3,4)$. Beta-lactam antibiotics like penicillins, cephalosporins and monobactams, have also been associated with immediate hypersensitivity reactions characterised by urticaria, angio-oedema, rhinitis, bronchospasm and anaphylactic shock within first hour of administration (5). A few reports of AAE have been reported in association with administration of food substances and medications in human immuno-deficiency virus (HIV) positive patients $(6,7)$.

We report a case of a seven year old, HIV elisatest positive girl admitted in a children's hospital in Nairobi, with the diagnosis of pneumococcal meningitis who developed severe non-tender oedema of the tongue and neck within six days of commencement of intravenous ceftriaxone treatment.

\section{CASE REPORT}

SWM was a seven-year old girl who presented at Gertrude's Garden Children's Hospital with a two-day history of severe headaches, neck pain and stiffness, vomiting and fever. Though she had not received any treatment for the current illness, she had previously been on various types of antibiotics for upper airway infections without any adverse events. She had no known previous allergy to foods or drugs. SWM was also a known asthmatic previously managed on interrupted courses of oral salbutamol as necessary. There was no history of travel to malaria endemic areas. Early development was normal and all childhood immunizations had been administered as per the Kenya expanded immunization program schedule, which included BCG, Oral polio, DPT and measles vaccine. She was the only child in the family and her father was reported to have died sometime back from probable leukemia, though acquired immune-deficiency disease exposure was suspected. 
Figure 1

Lateral view of the face showing a markedly swolen neck and tongue of a seven-year old, HIV positive girl during treatment for bacterial meningitis with ceftriaxone

At admission, SWM was found to be restless, febrile with a temperature of $38^{\circ} \mathrm{C}$ and had reduced level of consciousness. She had neck stiffness, hypertonic lower limbs but Kernig's test was negative. The pulse rate was 160 per minute, regular breathing, no subcostal recession nor flaring of ala-nasi. She had no subconjunctival pallour, oedema nor jaundice. The throat was normal and there was no evidence of dental caries or gingivitis. A diagnosis of meningitis was entertained and subsequently confirmed with isolation of streptococcus pneumonia, sensitive to ceftriaxone, in both cerebral spinal fluid and blood. Total leukocyte count was $17.8 \times 10^{9} \mathrm{~L}$ with an absolute neutrophil count of $15.5 \times 10^{9} / \mathrm{L}$. HIV 1 and 2 ELISA test was positive, blood smear for malaria parasites was negative, chest $\mathrm{X}$-ray was normal and renal function tests and random blood sugar were also normal. On admission to the intensive care unit, SWM was immediately commenced on antimeningitic dose of ceftriaxone, paracetamol and intra-venous fluids due to poor oral intake. Deteriorating level of consciousness on the day of admission led to endotracheal intubation and commencement of intravenous dexamethasone for probable increased intra-cranial pressure. Protrusion and gross swelling of the tongue was noted on the 6th post admission day (Figure 1) when the patient was still on respiratory support. There was no evidence of oral trauma, bleeding or local focus of infection in the mouth or neck. No swellings or oedema were identifiable in any other part of the body. Serum proteins, repeat urea, creatinine and electrolytes were normal. A clinical diagnosis of acquired angio-oedema of the tongue was made and ceftriaxone replaced with meropenem. Though the tongue swelling was regressing two days later, the patient died on the ninth day of admission. Laboratory facilities for determination of $\mathrm{C} 1$ esterase inhibitor, $\mathrm{C} 4$ or antibiotic antibodies were not available. Parents declined to have post-mortem done.

\section{DISCUSSION}

A clinical diagnosis of meningitis in a HIV positive patient was made in the index case right at the time of admission and appropriate antibiotic treatment commenced immediately. The causative agent was later confirmed to be $S$. pneumoniae, which was sensitive to ceftriaxone that the patient was already on. The condition of the patient did not show any marked improvement over several days. In Kenya S. pneumoniae has been shown to be responsible for $24 \%$ of meningitis in children admitted to a District General Hospital (8), but since the introduction of the Haemophilus influenza type $\mathrm{b}$ conjugated vaccine the proportion has risen to $52 \%$. Thirty six percent of children with pneumococcal meningitis died during hospital admission while 32\% developed neurological deficits upon discharge.

Occurrence of marked oedema of the tongue on day six of admission followed by neck swelling thereafter was an intriguing new development. Possibilities of both Ludwig's angina and angio-oedema were entertained. Ludwig's angina usually presents with a rapidly increasing cellulitis of the floor of the mouth characterised by a brawny induration of the floor and suprahyoid region bilaterally (9). As reported, there was no evidence of local inflammation in this case and the mouth looked otherwise normal, except for the oedema of the tongue. Though this condition has become increasingly rare due to better antibiotic access, de novo occurrence, without any predisposing factors, has been reported in children $(10,11)$. Compromised immune system as in HIV/AIDS has been cited among possible predisposing factors (12). In a series of nine cases, Srirompotong found streptococcus species to be the most common cause of the infection and was successfully treated with high doses of intra-venous antibiotics (9). Others have reported regression of cellulitis and oedema following addition of high dose dexamethasone 
to the antibiotic treatment(13). It is noteworthy that our patient was already on dexamethasone well before the onset of the tongue and neck swelling thus indicating the limitations of the steroid in prophylaxis in the presence of an ongoing antigenic challenge.

AAE has been reported in association with administration of certain food substances and medications in human immune-deficiency virus positive patients $(6,7)$. SWM was not on any such food substances but was on a third generation cephalosporin. Even in the absence of immune-deficiency, beta-lactam antibiotics are reported to be the most frequent causes of immediate immune allergic reactions. Onset is usually within one hour of their administration. Reactions are characterised by urticaria, angio-oedema, rhinitis, bronchospasm and anaphylactic shock (5). Mortality rate of angio-oedema has been previously estimated to range between $15-33 \%$ (1). The patient reported here developed the oedema and swelling over several hours and a decrease was evident a few days later following withdrawal of ceftriaxone, as would be expected in angio-oedema(14). We were, unfortunately, unable to confirm the diagnosis of angio-oedema.

Diagnosis of angio-oedema is based on demonstration of a low or absent serum compliment $\mathrm{C} 4$ or/and reduced $\mathrm{C} 1$ esterase inhibitor (14). Though overlooked in this case, skin testing for cephalosporin hypersensitivity should have been undertaken. Determination of specific IgE levels, where available, would similarly constitute good evidence for immediate allergic reaction in the absence of facilities for serum complement level determinations(5). It was the opinion of the authors that SWM experienced immediate hypersensitivity reaction from ceftriaxone but died from complications related to HIV and pneumococcal meningitis rather than angio-oedema.

Cephalosporin hypersensitivity should be considered in patients who develop angio-oedema on treatment. Though its diagnostic utility may need local validation, skin testing for patients with suspected antibiotic hypersensitivity in resource poor environments should be considered alongside determination of drug specific $\operatorname{IgE}$ antibodies, compliment $\mathrm{C} 4$ and $\mathrm{C} 1$ esterase inhibitor.

\section{REFERENCES}

1. Moore, G. P., Hurley, W. T. and Pace, S. A. Hereditary angio-oedema. Ann. Emerg. Med. 1988; 17:1082-1086.

2. Cicardi, M., Bergamaschini, L., Marasini, B., et al. Hereditary angioedema: an appraisal of 104 cases. Amer. J. Med. Sci. 1982; 284:2-9.

3. Agostoni, A, and Cicardi, M. Hereditary and acquired C1inhibitor deficiency: biological and clinical characteristics in 235 patients. Medicine (Baltimore) 1992; 71:206-215.

4. Cicardi, M., Zingale, L. C., Pappalardo, E., et al. Autoantibodies and lymphoproliferative diseases in acquired C1 -inhibitor deficiencies. Medicine (Baltimore). 2003; 82:274-281.

5. Romano, A., Mondino, C., Viola, M. and Montuschi, P. Immediate allergic reactions to blactams: diagnosis and therapy. Int. J. immun. Pharm. 2003; 16:19-23.

6. Kainer, M. A. and Mijch, A. Anaphylactoid reaction, angiooedema and urticaria associated with lamivudine. Lancet 1996; 348:1519.

7. Mazza, D. S., O'Sullivan, M. and Grieco, M. H. HIV-1 infection complicated by food allergy and allergic gastroenteritis: a case report. Ann. Allergy. 1991; 66:436-440.

8. Mwangi, I., Berkley, J., Lowe, B., et al. Acute bacterial meningitis in children admitted to a rural Kenyan hospital: increasing antibiotic resistance and outcome. Pediatr. Infect. Dis. J. 2002; 21:1042-1048.

9. Srirompotong, S. and Art-Smart, T. Ludwig's angina. A clinical review. Eur. Arch, otorhinolaryngol 2003; 260: 401-403.

10. Kurien, M., Mathew, J. Job, A. et al. Ludwig's angina. Clin Otolaryngol. 1997; 22:263-265.

11. Har-ELG, Aroesty, J. M., Shaha, A. et al. Changing trends in deep neck abscesses. Oral Surg. Oral Med. Oral. Pathol. 1994; 77:446-450.

12. LeJeune, H. B and Amedee, R. G. A review of odontogenic infections. J. La State Med. Soc. 1994; 146:239-241.

13. Saifeldeen, K. and Evans, R. Ludwig's Angina. Case report. Emerg. Med. J. 2004; 21:242-243.

14. Gompels, M. M., Lock, R. J., Abinun, M. et al. $\mathrm{Cl}$ inhibitor deficiency: consensus document. Clin. Exp. Immunol 2005; 139:379-394. 